ISSN: $1130-3743$

\title{
LA DIGITALIZACIÓN DE LA ENSEÑANZA O EL SUEÑO DEL APRENDIZ ELECTRÓNICO
}

\author{
Education goes digital or the dream about electronic \\ apprentice
}

\section{Le enseignement numérisé ou le rêve de l'apprenti électronique}

\section{Ángel SAN MARTín AlONSO}

Universitat de València. Facultad de Filosofía y Ciencias de la Educación.

Departamento de Didáctica y Organización Escolar. Avda. Blasco Ibáñez, 30. 46010

Valencia.Correo-e: asanmart@uv.es

Fecha de recepción: enero de 2005

Fecha de aceptación definitiva: abril de 2005

BIBLID [(1130-3743) 17, 2005, 157-184]

RESUMEN

El carácter constitutivo de las TIC en nuestra sociedad, nos lleva a integrarlas en un esquema holístico que denominamos hábitat tecnológico. Pensamos que esta perspectiva contribuye a superar engañosas dicotomías y permite situar el aprendizaje en un contexto complejo y tejido de tensiones entre polos opuestos (lo tecnológico y lo natural, entre lo material y lo simbólico, entre lo vulgar y lo científico, etc.). Las interacciones en ese entorno generan nuevas estrategias cognitivas y patrones culturales acordes con los medios utilizados, invitando también a pensar en nuevas pedagogías. El núcleo dinamizador de este hábitat es el potente sistema técnico que lo impregna y cohesiona con un discurso legitimador de las prácticas mediadas tecnológicamente. Más allá de esta circunstancia histórica, hemos de saber articular la convivencia de la escuela en el hábitat que nos toca vivir, y promover un aprendizaje contextualizado y comprometido con el análisis crítico del entramado tecnológico de la sociedad actual. 
Palabras clave: tecnologías de la información, sociedad del conocimiento, tecnología educativa, currículum, aprendizaje, e-learning.

\section{SUMMARY}

The constituted disposition of ICT in our society leads us to integrate them into a holistic diagram called "technological habitat". We think this perspective contributes to overcoming misleading dichotomys and it permits to place the learning in a complex context interwoven with tensions between opposite poles (the technological and the natural, the material and the symbolic, the common and the scientific, etc.). The interactions in that environment generate new cognitive strategies and a cultural standar which agree with the means used, inviting to think about new pedagogies too. The invigorating core of that habitat is the powerful technical system which impregnates it and cohesions with a legitimate speech of the trainings carried cut by means of technology. Beyond this historic circumstance, we should know how to articulate the school cohabitation in the habitat we have to live in, and to promote a knowledge in context engaged with the critic analysis of the technological framework of present society.

Key words: information technologies, knowledge society, education technology, curriculum, learning, e-learning.

\section{SOMMAIRE}

Le caractère constitutif des TIC dans notre société nous amène à l'intégration d'un schème holistique que nous appelons "habitat technologique". Nous pensons que cette perspective contribue à éviter de trompeuses dicotomies et permet de situer l'apprentissage dans un contexte entremélé de tensions entre les pôles opposés (la technologie face au naturel, la matière face au symbolisme, le vulgaire face à la science, etc.). Les intéractions dans ces conditions provoquent de nouvelles stratégies cognitives et des patrons culturels en accord avec les moyens utilisés, laissant penser aussi à de nouvelles pédagogies. Le noeud dynamisant de cet habitat est un puissant système technique qui l'imprègne et donne une cohésion pour un discours légitime des pratiques où la technologie intervient. Au delà de cette circonstance historique, nous devons de savoir articuler la vie commune à l'école dans l'habitat où nous vivons, et promouvoir l'apprentissage contextualisé et engagé avec l'analyse critique des réseaux technologiques de la société actuelle.

Mots clef: technologie de l'information, société de la connaissance, technologie éducative, curriculum, apprentissage, e-learning. 
[...] ando buscando un rincón donde encuentre un semejante, un hombre como yo, que llore y ría como yo río y lloro, y donde no haya una sola máquina y fluyan los dias con la dulce mansedumbre cristalina de un arroyo perdido en el bosque virgen.

M. de Unamuno (1913) Mecanópolis.

\section{1. ¿HASTA DÓNDE PUEDEN LLEGAR LAS TIC EN EDUCACIÓN?}

La idea nuclear del presente trabajo no es otra que llamar la atención sobre cómo el sistema técnico, valiéndose de su omnímodo potencial expresivo, promueve discursos orientados a legitimar su propia existencia. Cada vez resulta más difícil discernir entre lo que son hechos empíricamente contrastables de lo que es simple discurso. Nada ajeno, por lo demás, al modelo social actual en el que las "ideas y las imágenes son lo que realmente se compra y se vende", relegándose a un segundo plano su dimensión física (Rifkin, 2000, 73). Cierto que en determinados ámbitos, incluido el de la enseñanza, las tecnologías contribuyen a facilitar nuestras vidas en grado hasta ahora inimaginable, aunque quizá también a enturbiar aquella "mansedumbre cristalina". El problema estriba en que, con demasiada frecuencia, desde los estudios sociales se asumen tales discursos y los supuestos que los inspiran, contribuyendo inocentemente a fomentar expectativas de realidad. Lo que está sucediendo en educación, a nuestro entender, no está muy lejos de lo comentado: excesivas loas para resultados más que discretos, pero esos discursos son necesarios para la promoción social de las TIC.

Si el aporte de estas tecnologías es decisivo para explicar el avance experimentado durante estas últimas décadas en distintos campos de la investigación científica, en otros ámbitos como el de la nueva economía o en el del reparto de la riqueza cultural y tecnológica, los resultados alcanzados son bastante menos halagüeños. El llamado capitalismo popular alentado por la nueva economía, llevó a invertir en bolsa a pequeños y grandes ahorradores con el resultado final de más de 13 billones de dólares "perdidos" (aproximadamente unos 2.000 dólares por ciudadano del planeta, aunque sólo invierte en bolsa el $2 \%$ de la población), pues en esos tres años los valores de la nueva economía (el venerado Nasdaq) pasaron de valer algo más de 5.000 puntos a los 1.350 a comienzos de $2003^{1}$. Según estadísticas de la UNESCO cerca de 900 millones de personas del mundo actual "Son analfabetas declaradas -reconocen no saber leer ni escribir- dos tercios de las cuales son mujeres". En esta misma perspectiva macro, el citado organismo admite que "se necesitan 15 millones de docentes más para poder hacer llegar la educación a los países más pobres". Tomando ahora datos del Banco Mundial, "un 1\% de personas ricas de la población mundial reúne los mismos ingresos que se reparten un 57\%

1. Según J. Estefanía (2003) tres años después de aquella ensoñación, El Paîs, 17 de marzo. 
de gente pobre" (Llompart, 2002,16). ¿Qué han hecho o pueden hacer las TIC ante este panorama tan desolador? ¿Acaso puede la escuela, con el apoyo de las TIC, aminorar esos efectos indeseables?

La institución escolar sí puede y debe, como depositaria de la confianza pedagógica de enseñar, el desvelar o por lo menos no fomentar los despropósitos que acompañan al discurso dominante sobre las TIC. Es preciso desmitificar estos discursos y reparar con mayor detalle en el modelo de sociedad que desde esas tecnologías se nos está proponiendo, a fin de posicionarnos respecto a si es ése o no el modelo que deseamos. Tarea para la que tampoco la institución escolar tiene una buena posición, pues juega al tiempo el papel de medio y fin en la relación con las tecnologías. Fin porque debe educar para entender los nuevos mensajes de las TI y medio porque representa un espacio en el que las tecnologías deben estar para socializar en ellas a los escolares. Puede que en lo primero la escuela falle o no sepa muy bien cómo abordar ese objeto de educación, pero en lo segundo la institución juega un papel clave estratégicamente. Según datos relativos al País Vasco, la escuela es todavía el ámbito en el que los escolares acceden y trabajan con Internet, y eso que esta comunidad autónoma puso en marcha hace años programas de equipamiento tecnológico de hogares, lugares de trabajo y de ocio. Pese a todo, el $74,5 \%$ de los jóvenes entre 6 y 14 años accede a estas tecnologías en el centro de estudios, por lo que la función socializadora antes mencionada sigue siendo fundamental ${ }^{2}$. La cuestión crítica es que ahora la vanguardia de la innovación está pensando en aplicaciones tecnológicas en las que éstas sean el medio y el fin de la educación, promoviendo la alternativa de educación "sin escuela". ¿Puede seguir la "nueva educación" parecidos derroteros a los de la "nueva economía" si se deja deslumbrar por las TIC?

\section{LUCES Y SOMBRAS DEL SISTEMA TÉCNICO}

A modo de recurso explicativo de lo que hoy representan las tecnologías o, siendo más precisos, el sistema técnico que las genera, consideramos del máximo interés recurrir a una metáfora. Una metáfora que dé cabida a la complejidad inherente a las condiciones actuales de vida, las cuales se derivan de la necesidad de conjugar las exigencias de la naturaleza con las de los mundos creados por el ser humano. Entendemos que tales requisitos los cumple la metáfora que denominamos «hábitat tecnológico". Tomamos el concepto en la acepción acuñada por las ciencias ecológicas y no tanto por la geografía humana. Lo adjetivamos como

2. Encuesta sobre la sociedad de la información-Familia (2० trimestre de 2004). En www.eustat.es. Parecida tendencia se observa en los países europeos, donde los jóvenes ocupan el equipamiento del hogar a juegos y actividades de ocio, y el del centro escolar a tareas como la búsqueda de información o redacción de textos. Chiffres clés des technologies de l'information et de la communication à l'école en Europe. Bruxelles, Eurydice, Édition 2004. En www.eurydice.org. 
"tecnológico" para enfatizar que dicho hábitat lo vamos a estudiar asumiendo las múltiples variaciones que el sistema técnico introduce en el mismo, pero sin rango de factor único ni suficiente.

Si nos aproximamos a la definición que del término nos proporciona el diccionario de la Real Academia de la Lengua, nos encontramos que el hábitat es el conjunto de "condiciones geofísicas en que se desarrolla la vida de una especie". Aunque el significado original del término alude a lo local, aquí al adjetivarlo como tecnológico nos obliga a hacerlo extensivo a todo nuestro mundo (no es local sino global), pues todo él está trabado, con intensidad variable, por los artilugios emanados del sistema técnico. Por otra parte, con esta metáfora se pretende superar la dicotomía entre el "mundo material" y el "ciberespacio", cuya coexistencia lleva a establecer dualidades como la de pensamiento analógico frente al digital o la de inmigrantes frente a los autóctonos que son los jóvenes que han nacido en la cibersociedad (Lankshear y Knobel, 2003, 50 y ss.) ${ }^{3}$. Ahora bien, la utilización que hacemos aquí de dicha metáfora requiere alguna aclaración más:

a) El hábitat tecnológico no es algo dado ni irreversible, sino la resultante del encuentro fecundo entre la naturaleza y el deseo del ser humano de adaptarlo a sus proyectos. Proyectos que algunas veces alcanzan sus propósitos como el de eliminar en parte los inconvenientes de la distancia espacial a través de las telecomunicaciones y, en otros casos, tales proyectos se encuentran con la barrera infranqueable de la naturaleza, como sería, al menos de momento, el afán de crear máquinas pensantes. En todo caso y pese al empeño de la virtualización, es insoslayable la presencia de la naturaleza junto a otros muchos elementos directamente creados por el ser humano. Y de la relación dialéctica que se establece entre ambos surgen unas condiciones de vida que impone a los seres vivos la tensión de la acomodación permanente a aquéllas. Al menos así interpretamos la afirmación de Bateson $(1999,351)$ cuando dice que lo que ha evolucionado no es el caballo ni el pasto y puntualiza: "Lo que en realidad evolucionó es la relación entre el caballo y el pasto".

b) El hábitat tecnológico no es homogéneo ni uniforme, pues se constituye (tal como señalan los ecólogos), a partir de múltiples nichos ecológicos ("nichos tecnológicos" en nuestro caso), aportando diversidad a las condiciones de las vidas que transcurren en dicho entorno. No hace falta recurrir a las estadísticas para advertir que hay nichos tecnológicos hiperdesarrollados y otros muchos muy por debajo de lo humanamente razonable. Es el fenómeno que se identifica con el eufemismo de "brecha

3. Esta dicotomía surge a partir de la distinción establecida por $\mathrm{N}$. Negroponte entre el átomo como constitutivo de la "materia física" y los bits del "ciberespacio" que es en el que habita ya el ciudadano. Para A. MatTelart $(2000,418)$ esta dicotomía no es más que uno de los mitos con los que se publicita el futuro pensado por los neodarwinistas de la técnica. 
tecnológica”, y que para algunos analistas es la sonrojante dicotomía entre infopobres $v s$. inforricos.

c) No podemos ignorar que el modelo tecnológico aquí descrito es típicamente occidental y, en tal sentido, etnocéntrico. Los «infopobres" lo son porque no acceden al tipo y cantidad de información que el sistema técnico dominante certifica que es el solvente, no porque ellos carezcan de información valiosa para su estilo de vida. Los nichos tecnológicos menos tecnificados lo son en comparación con los que impone el estándar, no porque carezcan de tecnología, si bien ésta no es la reconocida por el paradigma hegemónico. Asumir esa condición relativa es fundamental para que el encuentro entre culturas, algo que ya está sucediendo en las aulas, sea dialogante y no trate de imponerse aquél como el más legítimo.

FIGURA 1

CONFIGURACIÓN HOLÍSTICA DEL ENTORNO NATURAL Y TECNOLÓGICO

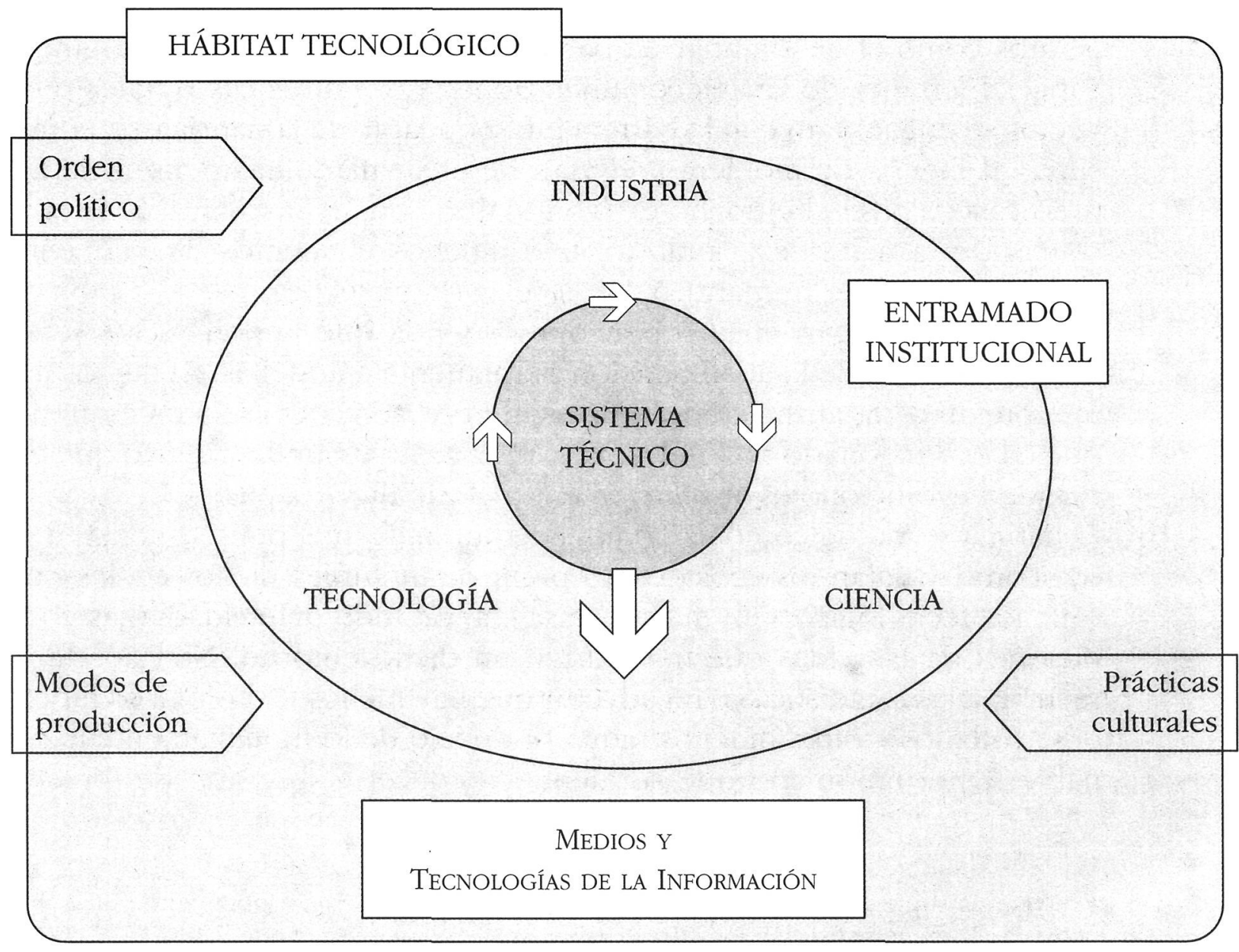


De manera que adjetivamos el hábitat como tecnológico porque en este momento histórico el sistema técnico interviene en todos los ámbitos constitutivos de nuestro entorno de vida. Intervenciones que, de un modo u otro, generan cambios en las condiciones del entorno, unas veces en el sentido planificado y otras muchas en direcciones imprevistas. Cuando se saluda sin reparo al sistema técnico, en términos globales, como liberador de muchas de las limitaciones del ser humano, no se presta suficiente atención a que también ese dominio conlleva no pocas controversias, como se desprende de las siguientes palabras:

El vertiginoso desarrollo científico-tecnológico del mundo actual está consiguiendo hacer realidad las fantasías de hace sólo unas décadas, con un extraordinario potencial para la transformación de la naturaleza y la satisfacción de las necesidades humanas. Sin embargo, ese desarrollo también ha planteado importantes desafíos sociales, éticos y legales acerca de peligros radicalmente nuevos por su magnitud y naturaleza... (López Cerezo y Sánchez Ron, 2001, 17).

Tratando de dar un paso más, ¿qué entendemos por "sistema técnico"? A partir de la idea de Quintanilla (1989), mantenemos que el referido sistema resulta del complejo entramado que une a la ciencia, a la tecnología y a la industria (ver Fig. 1). Y en estos momentos esa unión es de tal grado que resulta muy difícil, cuando no imposible, identificar los límites entre una y otra. Esto es, la industria, suplantando a los poderes públicos, patrocina aplicaciones tecnológicas que pretenden estar más allá del conocimiento consolidado, lo cual, a su vez, obliga a que éste avance a fin de dar cobertura a las últimas innovaciones tecnológicas. Las sinergias entre los distintos programas de investigación y desarrollo son totales y casi simultáneas para maximizar resultados, no en vano son los supuestos neoliberales los que dan cohesión ideológica a la totalidad del sistema técnico. Se instaura así un nuevo modo de producción de conocimientos que es lo que Echeverría (2003, 61 y ss.) caracteriza como tecnociencia.

El sistema técnico se configura a modo de bucle encantado que, ajeno en gran medida a los controles democráticos, se retroalimenta a sí mismo y va, progresivamente, ampliando las áreas de intervención localizadas en el hábitat antes aludido. Absolutamente nada escapa ya al interés del sistema técnico ${ }^{4}$, cuyo espectro recorre desde el descifrado del código genético hasta mecanizar una tarea doméstica tan sencilla como calentar el desayuno de cada mañana. Ahora bien, éstas no pasan de ser aplicaciones marginales de las innovaciones generadas desde diversos macroprogramas de investigación y, por ello, resultado de los protocolos de transferencia de tecnología. La rápida evolución y expansión del sistema técnico, según los expertos, está siendo posible gracias a los avances espectaculares en el

4. La noticia, a principios de octubre, la resaltaron diversos medios de comunicación, pues una multinacional de la electrónica de consumo había presentado un teléfono móvil para mascotas. Dicho teléfono, colgado al cuello del animal, le permitía a su dueño “comunicarse» con la mascota. 
subcampo de la informática y de las telecomunicaciones. Avances que, a su vez, permiten emprender proyectos más complejos en otros programas de investigación; es decir, el aumento constante en la capacidad de cálculo de los ordenadores permite intensificar los análisis en los programas de astronomía, física corpuscular o de microbiología, al tiempo que alguno de los descubrimientos en estos campos acabará aplicándose a la informática para aumentar de nuevo su potencial operativo.

En cualquier caso, lo que nos interesa resaltar aquí es que, simplificando un poco, se puede considerar que el núcleo duro del llamado sistema técnico lo constituye el ordenador o, mejor aún, la informática. Todo lo demás, de alguna manera, depende de él, de su capacidad de recibir, enviar y procesar datos conforme al patrón instalado en sus entrañas. La revolución digital, tecnológica o como quiera llamársele, pivota básicamente sobre la informática y las telecomunicaciones. Ahora bien, ¿qué no será capaz de hacer un ordenador? En términos más precisos Ramonet $(2000,17)$ plantea la siguiente cuestión: "¿qué cambio producirá una máquina, una máquina que, como el ordenador, no pretende sustituir al músculo sino que pretende sustituir al cerebro?". Como buen divulgador Ramonet nos lleva con su argumentación hasta dejarnos atrapados en: jla máquina puede suplantar al cerebro humano! Él conoce de sobra el fracaso de los programas tecnológicos que prometían la aparición en breve plazo de la inteligencia artificial. Promesa que, de ser asequible, tardará aún muchas décadas en ser operativa, entre otras razones porque todavía no se sabe muy bien cómo opera realmente nuestro cerebro ${ }^{5}$.

Mientras llega ese futurible, lo bien cierto es que la máquina está sustituyendo no sólo al músculo sino también descargando de cierta responsabilidad al cerebro humano. Lo cual va desde la realización de un cálculo simple o complejo hasta la interpretación de ciertas señales conforme a pautas programadas (suministrar al bombo de la lavadora la cantidad de agua en función del peso de la ropa introducida, por poner un ejemplo sencillo). Para los propósitos de este trabajo nos interesa de modo especial la alianza entre la informática y las telecomunicaciones (ya sea a través de cable o del espacio radioeléctrico), lo cual vendría a ser lo que se conoce como tecnologías de la información y de la comunicación (TIC en lo sucesivo). Y nos interesa por dos razones básicas:

a) Las máquinas y los contenidos simbólicos mediados por aquéllas se están instalando en el hábitat con tal intensidad que dejan escasos resquicios para otros modos de acción. Por lo que su creciente presencia está rompiendo el "equilibrio ecológico" del hábitat, lo cual se hace perceptible

5. Según José María Delgado, experto internacional en neurociencia, mucha "de la investigación sobre el cerebro no es ciencia, sino literatura". Y es que, para el profesor Delgado, de los millones de neuronas que constituyen el cerebro «Sólo hay tres o cuatro tipos que podemos explicar cómo funcionan’. El País, 22-9-2004. Desde luego que en tales condiciones difícilmente una máquina puede suplantar al cerebro humano. Quede pues la propuesta como un recurso literario más. 
desde la capa de ozono, el efecto invernadero hasta la aparición de enfermedades y epidemias cuya etiología remite a intervenciones tecnológicas (por ejemplo, el llamado "mal de las vacas locas" o encefalopatía espongiforme). No son menos preocupantes las interferencias que las TIC provocan en los estilos de vida y modos de interacción humana, hasta el punto de sustituir los viejos vínculos por otros nuevos. En este sentido apuntamos la incipiente doble identidad con la que hemos de convivir: por un lado la "analógica" que está asociada a nuestra persona física y, por otro, la identidad "digital" que generamos como usuarios de las TIC a partir del "rastro" que van dejando nuestros movimientos en la red.

b) En segundo lugar y tal vez el aspecto que más nos interesa, es que el sistema técnico no sólo produce conocimiento científico de circulación restringida, sino también abundante material simbólico diseminado entre la ciudadanía con el propósito de construir sociedad. Es decir, las TIC son el instrumento a través del cual el sistema técnico lanza los discursos mediante los que recabar legitimidad para sus proyectos e iniciativas. Internet, pongamos por caso, no sólo es una herramienta para obtener información valiosa por parte de los ciudadanos, es además en sí mismo un argumento que retroalimenta al sistema en los planos económico, ideológico y cultural. De algún modo se convierte en una estrategia de intervención con la cual introducir en la sociedad los cambios más coherentes con los requerimientos del sistema técnico. En definitiva, las TIC son la "escuela" desde la que el sistema técnico ejerce su propia pedagogía.

La proyección social de las TIC, al igual que ha sucedido con otros hallazgos en la historia de la humanidad, tiene sus luces y sus sombras, sin que ello niegue la relevancia de aquéllos. Desde esta perspectiva queremos señalar tres ámbitos que nos parecen significativos para el campo pedagógico.

1. El espejismo del "milagro económico". La promoción del negocio especulativo en torno a las TIC dio lugar al fenómeno conocido como "nueva economía" o $e$-business. Se entiende por tal "cualquier tipo de transacción comercial realizada on-line, incluyendo las distintas fases del intercambio, desde el marketing a la distribución, pasando por la prestación de servicios de postventa o medios de pago" (p. 179) 6 . Para Rifkin (2000, 32 y ss.), el "rasgo esencial del comercio en el ciberespacio es la conectividad", lo cual significa que productores, proveedores y hasta clientes comparten actividades e intereses. Es a finales de los 90 cuando las expectativas en este modelo alcanzaron su punto más álgido, puesto que a mediados de 2000 comienza a deshincharse la llamada burbuja tecnológica. Desde entonces, apenas cuatro años transcurridos, ya sólo quedan los rescoldos de aquella euforia

6. E-España2003. Informe anual sobre el desarrollo de la Sociedad de la Información en España. Madrid, Fundación Auna. 
que prometía cambiar el signo de los tiempos y, aparte de otros efectos, el logro más tangible es socavar un poco más los fundamentos de la convivencia entre los pueblos.

En este escaso margen de tiempo, no obstante, una elite de ejecutivos consiguió amasar grandes fortunas mediante el uso de información privilegiada y valiéndose de la "contabilidad creativa" en empresas que luego quebraron. Cierto que algunos de estos ejecutivos agitadores de la nueva economía están destituidos e incluso citados por la justicia, pero muchos de ellos se aprovecharon del momento para enriquecerse a costa del capitalismo popular que, en realidad, contribuyó a incrementar la "brecha económica" que lo es también tecnológica. Un dato para hacerse una idea de las magnitudes del fenómeno. La capitalización de la bolsa de Wall Street perdió, entre marzo de 2000 y julio de 2002,8 billones de dólares que viene a ser más de cuatro veces el valor de la deuda externa de todo el Tercer Mundo ${ }^{7}$. Telefónica acaba de vender su participación en el grupo de comunicación Pearson por menos de la mitad de lo que pagó cuando la compró en 1999. No obstante, hay casos más "ejemplares" en la gestión de la crisis. Algunos de los ejecutivos que por entonces obtuvieron suculentos beneficios y la justicia no ha penalizado sus prácticas, ahora revierten parte de aquéllos en obras filantrópicas vía fundaciones personales, tal es el caso de George Soros o Bill Gates. La fundación del patrón de Microsoft distribuye al año 1.200 millones de dólares para la investigación sobre la malaria, cantidad que supone el doble de lo que se invierte con idéntico propósito en el resto del mundo ${ }^{8}$.

2. Reingeniería de los procesos productivos y de sus instituciones. Terceiro y Matías $(2001,204)$ consideran que en esta "nueva revolución", similar a la de la agricultura y la industria, "lo sustancial es que tiene base en los continuos avances de la tecnología (en especial la informática y las comunicaciones) y en nuevas formas de administración que, en conjunción con los procesos de globalización y desregulación, han permitido elevar la productividad". Objetivo al que en buena medida también contribuyeron, según reconocen los autores citados, la estabilización de la inflación que permitió crear empleo sobre la base, eso sí, de precarias condiciones y salarios contenidos. Para Cabrillo (2000), el espectacular crecimiento de la economía no es ni mucho menos causa de las tecnologías de la información, y duda que tal fenómeno de expansión económica pueda ser calificado como de "nueva economía". En todo caso, si ésta es algo no es otra cosa que "la organización de los mercados y las instituciones lo que está marcando las diferencias en la evolución económica reciente de los países más desarrollados" (p. 84). Castells $(2001,118)$ considera, por su parte, que la nueva economía, "con el e-business como punta de lanza, no es una economía on line sino una economía cuyo motor es la tecnología de la información, que depende del trabajo autoprogramable y que está organizada

7. Estafanía, J. (2004) 75a aniversario del crash del veintinueve, El País, 18 de octubre.

8. PISAN, F. (2004) Bill Gates en Silicon Valley, El País-Ciberp@is, 21 de octubre. 
en torno a redes informáticas". Las cuales permiten constituir la que él llama "empresa-red", una nueva forma de organizar la producción industrial que es posible gracias a esas redes de telecomunicaciones.

La transformación de la vieja organización en empresa-red es lo que se conoce como reingeniería de las organizaciones. Según ilustra Sennett (2000, 50 y ss.) la reingeniería consiste en someter a las organizaciones a cambios profundos e inesperados, con el propósito explícito de mejorar la productividad y con el objetivo oculto de mejorar la cotización en bolsa. A tenor de los datos Sennett mantiene que estos procesos tan traumáticos no mejoran la productividad, pero sí la cuenta de resultados porque en realidad lo que se hace es despedir a mucho personal. De hecho, en los dos primeros años del presente siglo, unas 5.000 empresas "puntocom" desaparecieron o fueron adquiridas por otras, la destrucción de miles de puestos de trabajo (la industria informática y electrónica española hasta junio de 2002 perdió 10.400 puestos de trabajo; Deutsche Telekom planeaba a finales de 2002 despedir a 30.000 trabajadores para salir de la crisis y France Telecom propuso para el 2003 suprimir más de 13.000 puestos, etc.). Cierto que no se perdieron en términos absolutos todos esos puestos de trabajo, sino que parte de ellos se "deslocalizaron", lo cual supone un cambio importante en la organización de las empresas para adaptarse a las exigencias del momento. Tal vez por ello, sirva como ejemplo, el Gobierno autónomo madrileño organizó recientemente unas jornadas bajo el significativo título de "La tecnología como base para la creación de nuevas empresas", donde todas las actividades giraban en torno a cómo crear empresas a partir de las $\mathrm{TIC}^{9}$. Y es que las tecnologías fomentan estas "organizaciones ligeras" porque la economía en red «impulsa y se ve impulsada por una tremenda aceleración en la innovación tecnológica", siendo una de sus consecuencias el "acortamiento del ciclo de vida de los productos" (Rifkin, 2000, 34).

3. Cambios en los patrones culturales. Es obvio que la interacción con los artefactos tecnológicos genera nuevas prácticas culturales entre los ciudadanos de los nichos más avanzados (Fig. 1), lo cual, a su vez, estimula la innovación tecnológica. La máxima de esta dinámica es el "acceso" a esos bienes (materiales e inmateriales) que, ante todo, significa la "inclusión" del individuo en la sociedad red. Ahora bien, el acceso no es más que un producto ofrecido por la industria cultural a través de las TIC, cuyo contenido es todo aquello que afecta a la vida individual y da cohesión a la colectiva. Según Rifkin (2000, 190), la "cultura -las experiencias comunes que dotan de significación a la vida humana- está siendo arrastrada inexorablemente hacia el mercado de la comunicación, donde se renueva con criterios comerciales". La transformación del capitalismo industrial en capitalismo cultural está creando un boyante espacio de negocio (en la última década ha crecido dos veces más rápido que el resto del sector servicios),

9. Anuncio de las Jornadas en El País, 26-10-2004 y cuyo programa estaba en www.madrimasd.org. 
comercializando todas las formas de expresión artística y ahora también las experiencias de vida que van desde el turismo al entretenimiento o la formación. Rifkin advierte que los expertos en marketing y ciberespacio utilizan las TIC como "herramientas relacionales", manufacturando la experiencia personal y las distintas formas de expresión cultural para ofrecérselas a quienes puedan pagar por ellas.

Pese a este desmedido afán mercantilista y alejados de las posiciones deterministas respecto a las tecnologías, compartimos con Broncano $(2000,130)$ cuando mantiene que la "cultura tecnológica se convierte entonces en la capacidad social para captar y aprovechar las oportunidades" que surgen en el desarrollo de las acciones tecnológicas racionales. Pero esta racionalidad, según el mismo autor, para superar la acepción instrumental debe conjugar al tiempo la eficiencia, el valor con la referencia simbólica. Desde esta perspectiva la racionalidad tecnológica deja de ser un dispositivo estrictamente normativo para entenderse como el equilibrio entre las contingencias contextuales (el hábitat tecnológico del que venimos hablando) y los elementos estructurales del sistema técnico.

No se nos oculta que acceder a esta cultura tecnológica exige superar las numerosas coartadas que nos tiende la industria cultural, aprovechando la confianza que despierta precisamente el mismo sistema técnico. Y en este contexto resaltamos el hecho paradójico de utilizar artefactos técnicos pese a tener una cultura tecnológica bastante escasa. Al menos esto es lo que se desprende de los siguientes comentarios realizados por estudiantes universitarios usuarios habituales (el 98\% de los encuestados), de alguno de estos artefactos: informática, Internet, cámara digital o móvil ${ }^{10}$. Pues bien, traemos una pequeña muestra de las más de 600 respuestas recogidas a la pregunta: ¿Qué es la tecnología digital?

Entiendo por digital aquellas máquinas, que gracias a la tecnología, podemos descifrar, descodificar o interpretar los dígitos (números).

Algo que funciona mediante dígitos.

El control a través de un dedo, es decir, podemos hacer cantidad de acciones que antes requerían un esfuerzo físico, mediante la presión de un botón.

Es lo que hace posible que exista "Vía Digital” y te permite elegir la televisión que más te gusta.

También se les pedía a los encuestados que señalaran los términos o adjetivos que, a su entender, mejor caracterizan a la tecnología digital. Los señalados con mayor frecuencia fueron: calidad, avance, utilidad, innovación o control, además de algunos otros tan improvisados como: palpable, táctil, aparatos, imágenes o manipulación.

10. Estudio en fase de desarrollo sobre la "cultura tecnológica" de los estudiantes universitarios que son usuarios de las TIC. Convocatoria de proyectos propios de la Universitat de València, 2004.

(C) Ediciones Universidad de Salamanca

Teor. educ. 17, 2005, pp. 157-184 
La paradoja que destacábamos más arriba es que, pese a este dominio cultural tan pobre y desestructurado, algunos de estos estudiantes son auténticos "expertos" en el uso de la informática. Competencia que varios de ellos -no tanto de ellascentraban en su destreza para desbloquear y copiar videojuegos, música, películas, etc. Todos los demás reconocen manejar, con mayor o menor soltura, las aplicaciones informáticas más habituales: tratamiento de textos y navegación en Internet. La cuestión de fondo, pues, es que este "saber hacer" con las TIC puede convivir perfectamente con la más absoluta ignorancia respecto al modo en que operan las tecnologías que se manejan. Y a esto es a lo que nos referimos más adelante como "brecha tecnológica endógena" que, a nuestro entender, debe constituir el principal ámbito de trabajo pedagógico en las aulas.

\section{LA DIGITALIZACIÓN DE LA ENSEÑANZA}

Hace ya bastantes años Vaizey (1967), economista, académico y asesor de la UNESCO, planteaba algo muy oportuno a nuestros propósitos. Para el citado analista la "nueva pedagogía" se funda en los cambios aportados por la emergente tecnología de la educación, cuya evolución es imprevisible y, desde luego, introducirá cambios diversos en la enseñanza. En cualquier caso, mantiene el autor, hay suficiente información científica y experiencias en los países más avanzados, según las cuales las nuevas técnicas de enseñanza (entre las que destaca el cine, la radio, la televisión, el magnetofón o la máquina de enseñar), constituyen «la semilla de una importante revolución de los métodos pedagógicos, similar a la que se operó cuando comenzaron a introducirse los libros de texto con los que se pretendía disponer el material de manera ordenada y atractiva..." (p. 207). Y algunas páginas más adelante plantea un interrogante aún vigente: “¿Se puede concretar qué es en definitiva lo que todas estas nuevas técnicas pedagógicas -mero prólogo a la oleada de renovación técnica que se avecina- representan para la educación de nuestros dias?" (p. 214).

Varias décadas después del texto precedente y también preconizado por la UNESCO, en el informe coordinado por Delors (2001) se afirma que "Como instrumentos de educación de los niños y de los adolescentes, las nuevas tecnologías brindan una posibilidad sin precedentes de poder satisfacer con toda la calidad necesaria una demanda cada vez más amplia y cada vez más diversificada" (p. 202). Y poco más adelante la Comisión responsable del referido informe recomienda que, habida cuenta de la revolución digital experimentada durante la última década, "la cuestión del empleo de las nuevas tecnologías en la educación es una decisión de carácter financiero, social y político y debe situarse en el centro de las preocupaciones de los gobiernos y de las organizaciones internacionales" (p. 203).

En efecto, mientras esos organismos se ocupan de articular políticas que traduzcan en prácticas tales "preocupaciones", desde el sector industrial van tomando posiciones y experimentando modelos de enseñanza calificados ya como electrónicos o 
digitales. Pero, ¿en qué consisten esos modelos de formación? A partir de las experiencias puestas en marcha con éxito por diferentes multinacionales (desde Total a IBM, pasando por DigitalThink), Gil (2001) advierte que estamos ante "una auténtica reingeniería de la formación hecha ahora posible por la tecnología" (p. 14). Y bastantes páginas más adelante destaca que los componentes fundamentales de estos nuevos modelos serían: "Crear, gestionar, administrar los contenidos, difundir recursos de Web Based Training, seguir la trayectoria individual de los aprendices, gestionar los tutores online, todo lo cual conduciría a los Learning Management Systems (p. 57). Como el propio autor señala en numerosas ocasiones, estos modelos de formación son posibles gracias a las casi ilimitadas prestaciones de tecnologías como la informática y las telecomunicaciones, que permiten tratar la información como nunca antes se había podido hacer. El modelo pedagógico subyacente es el que se inspira, según el autor citado, en los tres principios siguientes: justo-lo-bastante, justo-a-tiempo y coste-justo.

Más allá de las consideraciones que merezcan tales propuestas, lo cierto es que la preocupación por mejorar la relación entre las tecnologías y la enseñanza se remonta a varias décadas. Lo novedoso del momento actual es que el potencial de las tecnologías permite plantear el problema únicamente en términos de la información. Los flujos de información, magnificados y de perfil borroso, ahora se equiparan semánticamente a comunicación, a pedagogía y, por supuesto, a conocimiento. Prevalece la dimensión instrumental de la información, como se desprende de la siguiente observación de Sanz-Magallón (2000, 9): una "edición diaria del New York Times contiene más información de la que tendría un ciudadano promedio del siglo xvII durante toda su vida. En los últimos cinco años se ha generado más información que en los 5.000 anteriores, y esta información se duplica cada cinco años". Ahora bien, ¿qué se entiende por información en tal contexto y cómo se computa? Sin duda se refiere a esa mercancía que las tecnologías producen, distribuyen y almacenan facilitándole, a su vez, al ser humano el acceso y manejo de la misma. Por tanto, ¿qué es lo valioso de este fenómeno: la información disponible o el hecho de poder producirla industrialmente? Ni el autor antes citado ni otros muchos entran en semejante cuestión, más allá de exponer algunas generalidades. Tal vez por ello resulte excesivo hablar de "sociedad de la información" y sí más preciso, como hace Castells, de sociedad "informacional". Este informacionalismo consiste en que "las actividades decisivas de todos los ámbitos de la praxis humana se basan en la tecnología de la información, organizada (globalmente) en redes informacionales cuyo centro es el procesamiento de la información (símbolos)" (Castells e Himanen, 2002, 17).

Es a partir de la concepción instrumentalista de la información desde donde se da un salto cualitativo importante para hablar hoy sin rubor de la sociedad del conocimiento. Según Sanz-Magallón $(2000,10)$ es "aquélla en que los ciudadanos disponen de un acceso prácticamente ilimitado e inmediato a la información, y en la que ésta, su procesamiento y transmisión actúan como factores decisivos en toda la actividad de los individuos, desde sus relaciones económicas hasta el ocio 
y la vida pública" (p. 10). A tenor de lo cual da la impresión que fuera de las redes tecnológicas no hay nada, es el vacío absoluto. Se niega así la existencia de lo que no esté dentro de aquéllas o, como mucho, se le reconoce el estatus de "lo otro", de lo extravagante atrapado en las tinieblas del pasado. La duda surge de inmediato: ¿dónde se sitúa el conocimiento: en los "almacenes" de la red o en la mente de los usuarios? Como buen neoliberal, ideología en la que se sustenta mayormente este tipo de planteamientos, el citado autor responde que está en la red, listo para que los usuarios accedan a él si quieren permanecer conectados al mundo. Sin embargo, esta vía no permite ir mucho más allá de teorizar sobre lo que la red tiene de expendeduría de información y esto, desde el punto de vista pedagógico, tampoco tiene demasiado interés. Tal es así que, con claridad meridiana, García Carrasco y García del Dujo $(2001,278)$ mantienen: "El problema pedagógico y educativo no es un problema de mecanismos, sino del contenido con el que esos mecanismos operan".

Para Bunge (2002, 23 y ss.), crítico mordaz de la "infomanía" alentada por los usos más habituales de Internet, admite que este medio, no obstante, juega un papel fundamental entre los científicos de los distintos ámbitos de investigación, porque se rigen por un ethos basado en la búsqueda de la verdad, el compartir información de sus respectivas líneas de trabajo y de crítica constructiva entre ellos. En este caso Internet está facilitando el progreso científico, pero esto no tiene nada que ver con la "industria del conocimiento" objetivada en el ciberespacio, del cual dice Bunge que «es el paraíso del relativista cultural». Y añade a continuación: «...la Red se ha transformado en un obstáculo para la educación seria, dado que muchos estudiantes prefieren las dudosas vulgarizaciones que se hallan en la Red, a la esforzada búsqueda en una biblioteca" (p. 29) ${ }^{11}$. Aunque Bunge no lo propone abiertamente, sí se deduce de su planteamiento la doble cara de la red, por un lado estaría la que transfiere mensajes encriptados con alto valor entre miembros de ciertas elites como las de científicos y, por otro lado, estaría la red abierta a todos que nutre la boyante industria del conocimiento y de la que no se puede sacar demasiado provecho cognoscitivo.

Aquí nos interesa esta segunda cara que es la más visible de la tecnología de la información, en la medida que es la de mayor relevancia pedagógica puesto que la educación ha devenido en importante área de negocio de la industria cultural. En este caso la cuestión nuclear sería: ¿hasta qué punto los ciudadanos se apropian del conocimiento que circula por las redes convirtiéndolo en propio? Desde luego que, dada la naturaleza del proceso, el asunto no se puede despachar recurriendo a las reglas del mercado. Pues como destaca Llano $(2000,163)$, "El conocimiento, en cambio, es un crecimiento interno, un avance hacia nosotros mismos, un enriquecimiento

11. En contraste a semejante postulado, J. GIMENo (2001, 70) afirma: "La Red por sí sola se convierte en conocimiento generalizado, algo que no le había ocurrido, ni de lejos, a la biblioteca". 
de nuestro ser práctico, una potenciación de nuestra capacidad operativa..... Y un poco más adelante precisa:

...la capacidad de llegar a saber más no se puede remitir a algo objetivo, a los propios datos o a sus combinaciones y recombinaciones más o menos automáticas. La capacidad de saber más apela en directo al sujeto del conocimiento, es decir, a la persona humana. Lo que nos permiten los ordenadores e ingenios telemáticos es descargarnos de las tareas rutinarias de buscar información, almacenarla y -en alguna medida- organizarla y procesarla. Quedamos así en franquía para ponernos a realizar esa misteriosa operación de lo que sólo nosotros, los seres humanos, somos capaces: pensar (p. 164).

En sentido parecido se pronuncia Bunge (2002, 25 y ss.) cuando afirma taxativamente que "Sólo un cerebro viviente y bien pertrechado puede inventar ideas radicalmente nuevas, en particular problemas, analogías, principios de elevado nivel y algoritmos". Además y a diferencia de las computadoras, añade el citado autor, ese cerebro sí es "capaz de emitir juicios morales autónomos". Ahora bien, para potenciar todas estas capacidades el ser humano, joven o no, debe ser ayudado de alguna manera, lo cual vendría a ser todo lo relativo a los modelos y estrategias de enseñanza. Las decisiones que se adopten en este plano dependen, en gran medida, del enfoque psicológico (conductista, sociocultural o constructivista) como guía de explicación del proceso de apropiación del ser humano, de cómo va elaborando sus estructuras de pensamiento. No es objeto de este trabajo considerar las múltiples revisiones que sobre este particular se han realizado, me limitaré a señalar un par de aspectos que considero fundamentales desde la perspectiva de la enseñanza digitalizada.

a) El alto desarrollo de la tecnología disponible permite someter a tal grado de tratamiento la información que cada vez la intervención del usuario es más simple o, dicho de otro modo, con menor conocimiento las máquinas le permiten hacer tareas más complejas (visto desde el plano del usuario no del ingeniero o del creativo de net art) ${ }^{12}$. Estamos ante lo que llaman "tecnología incorporada" que viene a ser el conjunto de tareas que el artefacto -digamos el ordenador- es capaz de realizar por sí solo (Martín, 1999, 3). Fenómeno que nos sitúa ante la paradoja siguiente: hasta ahora el propósito de enseñar exigía disponer un método a tal fin, sin embargo, nos encontramos que la mayoría de esas disposiciones metodológicas han sido asumidas (están automatizadas) por parte del artefacto. Con frecuencia se argumenta que la información está en la red, de manera que lo pedagógicamente importante es enseñar a los estudiantes a ordenar, clasificar, jerarquizar, interpretar

12. La tecnología de la información trabaja tanto para facilitar la relación del usuario con ella, como para crear y ordenar inmensas bases de datos, la realidad virtual o lo que ahora llaman realidad aumentada. Destacamos, en este sentido, la batalla tecnológica y comercial que libran compañías como Google, Yahoo, Microsoft o AOL por que su "buscador" lidere el mercado. 
o filtrar esa información. En el documento del Ministerio de Educación y Ciencia con el que promueve el debate sobre la reforma, la propuesta 5.4 encomienda a las Administraciones educativas el fomento de "la adquisición de destrezas y habilidades relacionadas con la búsqueda, selección, análisis y organización de la información y el dominio funcional de las tecnologías de la información y la comunicación" (pp. 69-70) ${ }^{13}$.

El problema estriba en que muchas de esas tareas, incluso algunas de alcance simbólico o tan delicadas como la evaluación, ya las realizan distintas aplicaciones informáticas. Tal vez por esta razón Sarramona (2000, 22), insiste que el punto clave para lograr el aprendizaje deseado, "lo constituye el tipo de actividades que los alumnos se vean precisados a realizar". De todos modos, no nos engañemos, la aludida reingeniería pedagógica viene a ser la traducción en algoritmos (potencia de procesamiento más diseño gráfico) de las viejas estrategias de enseñanza, por lo demás, proceso idéntico a lo que sucede en el sector industrial y en el de servicios. Dar respuesta a semejante dinámica se ha convertido en un "problema técnico" propio de nuestro tiempo, mientras que reconstruir las condiciones de enseñanza dentro o fuera de la institución escolar, con o sin las TIC, es "político" y esto ahora ya no despierta demasiado interés en los ámbitos pedagógicos.

b) La segunda cuestión hace referencia a que el desarrollo de las tecnologías es de tal magnitud que genera dentro del hábitat (ver Fig. 1) lo que se conoce como "brecha tecnológica" (o digital). El fenómeno es tan complejo y tiene tantas implicaciones que se presta a análisis desde diversas perspectivas, tales como «su origen, su entidad y su singularidad o pluralidad" (Vázquez, 2003, 22 y ss.) ${ }^{14}$. No podemos detenernos aquí en los diferentes enfoques de este fenómeno, para nuestro propósito es suficiente con destacar el doble sentido que le atribuimos. Por un lado y según Ballestero (2002, 73), la brecha digital vendría definida por cuatro elementos: disponer o no de ordenador, acceso o no a Internet, saber o no "navegar" en la red y, por último, "La capacidad adecuada para poder hacer que la información accesible en la red pueda ser convertida en "conocimiento" por el usuario". Pero esto es posible si el usuario conoce cómo la tecnología produce y presenta (visualiza) la información mediante los formatos electrónicos, de lo contrario el usuario se separa/distancia de las operaciones que realiza la máquina. Lo cual permite plantear una segunda dimensión del fenómeno que nos ocupa: la «brecha endógena" que se localiza en el núcleo mismo del binomio sujeto-TIC. Lo importante ya no es únicamente acceder a la información, sino que para apropiarse cognitivamente de ella es preciso conocer las condiciones de su producción, en la medida que éstas intervienen en la información como "para-textos" condicionando

13. En Una educación de calidad para todos y entre todos. Madrid, Ministerio de Educación y Ciencia.

14. El profesor Vázquez concluye el epígrafe afirmando que "la posibilidad de atenuar la brecha digital pasa por la promoción de la educación tecnológica en las aulas escolares" (p. 26). 
su significado. ¿Cómo se puede elaborar conocimiento a partir de una información de la que se desconoce su genealogía? Lo que maravilla y cautiva es que la tecnología actual permite, mediante un corto itinerario de rutinas, acceder a un universo inagotable de "información", quedando a merced del usuario el hacer o no una "lectura comprensiva" de aquélla. Ahora bien, ¿es posible realizar este tipo de lectura con el bagaje cultural que reflejamos más arriba entre estudiantes universitarios? La cuestión no es únicamente la dificultad de alcanzar un cierto grado de comprensión, sino que al intensificar de modo rutinario la interacción con la máquina se vacía aquélla de contenido cultural.

Como consecuencia de las observaciones precedentes, destacamos que el modelo de enseñanza ofrecido a través de las TIC no es digital únicamente por el soporte, sino porque la digitalización implica una transformación profunda del modelo mismo. Ya hemos señalado que las pautas metodológicas quedan incorporadas a las tecnologías y el usuario sólo tiene la disyuntiva de activarlas o no en la "navegación" con la aplicación informática. Si a esto añadimos que la relación del usuario con la máquina se rige por pantallas o interfaces (iconos), advertiremos entonces que se ha producido un cambio radical en las formas de enseñar, en el sistema de orden que regía la transmisión escolar del conocimiento (San Martín, 1995). En el mismo sentido Gimeno $(2003,218)$ habla de la "pérdida de vigencia del régimen de lectoescritura que la escuela ha establecido". Las pantallas se configuran mezclando palabras, iconos y sonidos cuyo significado es una instrucción concreta que el usuario debe activar o no para que la máquina la ejecute. Aparece así un modelo de enseñanza que podríamos calificar de ubicuo, autosuficiente y tecnológicamente determinado, por lo que para interactuar con él no se requiere un especial dominio del lenguaje oral o escrito.

\section{EL APRENDIZ ELECTRÓNICO}

El rótulo de partida no deja de expresar una fantasía tecnicista, sin embargo entendemos que es la respuesta lógica al epígrafe precedente. Pero si en estos modelos lo fundamental no es ya la oferta sino la demanda y la información muta en conocimiento, entonces el aprendizaje deja de ser un proceso sociocultural de cada individuo para convertirse en algo estrictamente tecnológico. Proceso en el que el sujeto que aprende, pese a ser el verdadero protagonista, queda oculto tras la cortina del aprendizaje electrónico o, si se prefiere, e-learning. Utilizamos, pues, la expresión "aprendiz electrónico" únicamente como recurso retórico para llamar la atención sobre la contradicción pedagógica de tales planteamientos. Dicho en términos más directos: "De ahí que el mejor sinónimo de "sociedad del conocimiento" no es otro que "sociedad del aprendizaje" , sociedad en la que siempre es necesario saber más (Llano, 2000, 165). Desde luego que ahora no debe ser mucho más necesario de lo que lo fue y seguirá siendo en las distintas formaciones sociales que articulan la vida colectiva del ser humano. En cualquier caso, el 
prototipo de aprendiz electrónico dónde se forma, cómo y qué aprender, tres pilares básicos que desarrollamos con algún detalle a continuación.

\subsection{Hacia nuevos entornos de aprendizaje}

De las cuestiones formuladas más arriba la que parece irse despejando con mayor claridad es la de ¿dónde se aprende? La respuesta, al menos para los entusiastas de la sociedad del conocimiento, es que eso se hace fuera de la escuela, del sistema reglado de enseñanza, puesto que tal objetivo se alcanza exponiéndose a la información que emana de los múltiples artefactos y dispositivos dispuestos a tal efecto. Y para reforzar esta opción, la práctica más habitual es criticar ferozmente al sistema reglado, al tiempo que se le niega toda legitimidad y competencia para propiciar el tipo de aprendizaje requerido por la sociedad de nuestros días. Tales críticas se presentan de maneras muy distintas.

A modo de ilustración tomamos un titular de prensa de la sección de deportes, en el que se podía leer lo siguiente: "Ir a clase es perder el tiempo" ${ }^{15}$. El juicio sumarísimo se pone en boca del ajedrecista, niño prodigio de 15 años, T. Radyábov pronunciada al día siguiente de ganar en Linares a G. Kaspárov. Lo llamativo es que con esa frase se titula, a cuatro columnas, una larga entrevista en la que dice otras muchas cosas interesantes. Puestos a ser sensacionalistas se podría haber tomado como titular lo que también dijo el entrevistado y es que el jamón "contribuye esencialmente a que me guste España". Pero si hasta en la sección de deportes se opta por un juicio tan lapidario es porque la redacción valoró su mayor eco entre los lectores, al tiempo que reforzaba un poco más la devaluada imagen de la institución escolar. Eso sí, el muchacho alardea de los notables y sobresalientes obtenidos en el curso anterior, reconociendo a continuación que los domingos se dedicaba en exclusiva "a estudiar y hacer los ejercicios del colegio".

La referencia precedente ilustra con claridad esa idea según la cual la escuela, representante del viejo orden, ya no sirve para la dinámica impuesta por la sociedad del conocimiento en la que el aprendizaje ha de ser una constante de sus miembros. Ahora bien, ¿por qué se excluye, explícita o implícitamente, a la institución escolar de la llamada sociedad del conocimiento? Hay bastantes indicios para argumentar que tanto la estructura como las reglas que rigen la distribución del conocimiento del viejo modelo institucional no son compatibles con el paradigma pedagógico emergente. Y no lo son porque éste ahora requiere "aplicar fórmulas de one to one en el seno de la propia formación. Es conseguir elaborar nuevos recursos y un sistema de producción del acto pedagógico que alcance no a una sino a mil personas; y que trate también a cada uno como un individuo con necesidades únicas y diferenciadas” (Gil, 2001, 200). 
Pero ese individualismo rampante se refuerza cuando en el nuevo orden las instituciones deben limitarse a ofertar oportunidades para que el individuo se desarrolle. Nos encontramos así que en la presentación oficial del Plan Info-XXI, promovido desde las altas instancias del Estado en respuesta a la Iniciativa Estratégica para el Desarrollo de la Sociedad de la Información de la Unión Europea, el entonces presidente del Gobierno señaló que la Sociedad de la Información sería "más ajustado a la realidad" denominarla Sociedad de las Oportunidades, puesto que aquélla "se basa, justamente, en la primacía de la iniciativa individual" ${ }^{16}$. El Plan Info-XXI se puso en marcha a finales del año 2000 , dotado con varios cientos de millones de pesetas, tres años de duración y con más de trescientas acciones y proyectos propuestos por las Comunidades Autónomas, Ayuntamientos, la Administración central y otras entidades públicas y privadas.

Por lo que se desprende de las tres referencias precedentes, ni los creadores de opinión pública, ni los estrategas de la sociedad de la información en consonancia con las políticas de los gobiernos, parecen confiar demasiado en la escuela. Entre otras razones porque no está al alcance de la vieja institución el producir en masa el acto pedagógico a petición de cada usuario, de manera que esa oferta en tales términos sólo se puede hacer fuera de la escuela. Ahora bien, mientras llega ese momento dulce de la externalización de la educación, la fase previa debe ser la de incorporar las TIC a los ámbitos escolares. Pese a la incertidumbre que ahora mismo despierta tanto el negocio como el desarrollo inmediato de las tecnologías, se insiste una y otra vez en que las TIC deben entrar en las aulas o, mejor aún, para algunos autores la educación debe someterse a la lógica de aquéllas. Es más, no actuar en tal sentido es volver a las cavernas, es permanecer atrapados entre los apocalípticos. El nuevo reto de los sistemas educativos, especialmente de cara a los más jóvenes, es propugnar «la adquisición de la capacidad intelectual necesaria para aprender a aprender durante toda la vida, obteniendo información digitalmente almacenada, recombinándola y utilizándola para producir conocimientos para el objetivo deseado en cada momento" (Castells, 2001, 307).

Según resalta Hargreaves (2003, 31 y ss.), las reformas educativas promovidas en la inmensa mayoría de los países del mundo, «se desplaza(n) hacia la creación de escuelas para la sociedad del conocimienton. Asimismo constata que numerosos escritores, intelectuales y responsables políticos de orientaciones ideológicas muy distintas coinciden en resaltar que es esencial en estos momentos configurar "un sistema educativo público fuerte y mejorado". En otras palabras: «Para los pensadores críticos de hoy día, hay que difundir -más que difundir, socializar- el conocimiento para que la humanidad comprenda la realidad del mundo, con sus peligros y sus oportunidades, y la educación es la puerta a ese conocimienton (Llompart, 2002, 16). Ahora bien, es el propio Hargreaves quien advierte que muchas de las iniciativas de

16. Discurso del presidente del Gobierno, don José María Aznar, en la presentación del Plan de Acción Info-XXI. Vitoria, 24 de enero de 2001. En: www.infoxxi.es. 
integración de las tecnologías de la información ofrecen «un notorio ejemplo del fracaso de la creatividad en el cambio educativo" (p. 34). De manera que la pregunta surge de inmediato: epor qué tanta buena intención y tanto empeño en la incorporación de las TIC a los ámbitos escolares no genera resultados más alentadores?

De la mano del propio Hargreaves encontramos una primera explicación: "Los problemas de la ingenuidad técnica en el uso de la tecnología de la información en las escuelas ya no son grandes. Los principales problemas tienen que ver con la ingenuidad organizativa y social». $Y$ añade un poco más adelante que en la mayoría de los centros, sobre todo en los de secundaria las tecnologías se han instalado en laboratorios y aulas especiales y, claro, mediante esta fórmula "la gramática tradicional de escolarización con su sistema de una asignatura, un profesor, una clase, quedaba intacta" (p. 34). En efecto, quienes como el autor citado pensamos que es la escuela pública la que debe seguir contribuyendo y apropiándose de la sociedad del conocimiento, no podemos por menos de lamentar la forma en la que se han incorporado hasta el momento las tecnologías de la información a los centros escolares. La razón de resultados tan mediocres obtenidos en la mayoría de las experiencias, no se deben únicamente a la "ingenuidad organizativa" sino también y de modo especial a la "ingenuidad tecnológica». Esto es, no basta con tener el dominio técnico de un artefacto, es necesario comprender también que éste forma parte de un sistema bastante más complejo -tal como tratamos de resaltar en el epígrafe segundo- que desde luego no es compatible con las estructuras burocráticas de las organizaciones modernas. Operan con lógicas radicalmente distintas y por eso, a nuestro entender, las TIC más avanzadas sólo entrarán en la escuela de forma transitoria, para acabar imponiendo su poderío en ofertas de formación abierta y accesibles al usuario desde su entorno inmediato. Por supuesto, serán ofertas al margen de la institución escolar y en directa competencia con las de ésta, pues el e-learning no es otra cosa que un primer esbozo de esa "nueva educación" que se promete con las TIC.

\subsection{Los senderos del aprendizaje electrónico}

En palabras de Castells $(2001,308)$,

No hay reestructuración más fundamental que la del sistema educativo. Y el caso es que muy pocos países e instituciones se la están planteando realmente porque antes de comenzar a cambiar la tecnología, a reconstruir las escuelas y a reciclar a los profesores, necesitamos una nueva pedagogía, basada en la interactividad, la personalización y el desarrollo de la capacidad de aprender y pensar de manera autónoma. [...]. Y esta nueva perspectiva educativa constituye todavía una tierra virgen.

De acuerdo, tiene razón el profesor Castells al señalar que se carece de una "nueva pedagogía" que articule la relación de la escuela con las TIC, pero semejante constatación suscita otra cuestión: ¿acaso estas tecnologías requieren de 
nueva o vieja pedagogía para llegar a los ciudadanos? La experiencia demuestra machaconamente que aquélla no es necesaria, al menos en la acepción más corriente del término pedagogía. Además, ¿qué teórico de la educación a partir de la Escuela Nueva ha dejado de reconocer que la educación debe ser interactiva, personalizada y fomentar la autonomía del individuo? Con unos u otros matices, la mayoría de las figuras de la pedagogía han reconocido que ésos son algunos de los atributos que deben orientar a la educación. En consecuencia, ¿qué connotación peculiar les atribuye a los mismos Castells?

No es fácil desentrañar su significado implícito, pero en la siguiente afirmación podemos encontrar indicios relevantes: "la fuente de la productividad y la competitividad es la mano de obra capaz de programarse a sí misma" (Castells e Himanen, 2002, 18). Si así es la sociedad del conocimiento constituida sobre el hábitat tecnológico (Fig. 1), cuyos nichos laborales tienen unas exigencias muy concretas, lo lógico -según estos planteamientos- es que se eduque a los ciudadanos conforme a las competencias demandadas por esos nichos laborales. Lo cual es tanto como afirmar que los sujetos deben aprender a manejarse en el lenguaje informático, cuyo fundamento es el código binario extremadamente complejo para los expertos que lo elaboran y muy sencillo para el usuario que puede acceder a su manejo mediante el ensayo y el error. A través de la "pedagogía del interfaz", creada por los ingenieros informáticos y diseñadores gráficos, se conduce al usuario para que interactúe con la máquina de modo individual y acceda a información que habrá de decidir luego qué hacer con ella.

Desde la lógica del lenguaje informático no caben pedagogías, ni viejas ni nuevas, el usuario sólo tiene que dejarse llevar por los distintos itinerarios preestablecidos y señalados por los interfaces. No se nos oculta que esta posición es un poco drástica, pero hay millones de usuarios de ordenadores y de Internet que, como mucho, han hecho un cursillo de iniciación y sobre todo ejerciendo el "boca a boca" es como consiguen un manejo experto de las TIC. Ésta es, en todo caso, la doble vertiente de las generaciones más avanzadas de las tecnologías: a mayor tecnología incorporada menor competencia se requiere del usuario. Para avanzar en esta modalidad de "aprendizaje" se requiere una actitud indagatoria, paciente y sin miedo a realizar ensayos, a probar lo nuevo para luego extraer las consecuencias pertinentes. En suma, experimentar para derivar conclusiones con las que alimentar un pensamiento eminentemente inductivo. Desde el punto de vista pedagógico esto es lo coherente con el aprender a aprender, el saber aprender y el autoaprendizaje y todas ellas conducen directamente al autodidactismo. Quien así se forma no necesita más pedagogía que la libertad y los medios tecnológicos y económicos para interactuar con las máquinas.

Pero este aprender a aprender sin que nadie enseñe nada suscita una paradoja en el plano pedagógico que creemos merece unas pocas líneas. Según Bruner (2004, 23 y ss.) hay dos modalidades de pensamiento: uno paradigmático o lógicocientífico construido con reglas formales y comprometido con la verdad, mientras que el segundo sería de corte narrativo, sujeto a reglas menos estrictas, que sólo 
pretende ser verosímil. Entre ambos no hay una separación radical sino que tienen puntos en común, pero operan con distintas estrategias epistemológicas y por ello producen representaciones del mundo diferentes, en un caso pretende ser verdadero (la ciencia) y en el otro sencillamente creíble. Desde este doble plano se puede afirmar que el lenguaje informático es consecuencia y opera conforme a la modalidad paradigmática, sin embargo los usuarios pueden construir con él narraciones plenas de creatividad (un chat, un texto, un videoclip, un fotomontaje, etc.). Por otra parte, el currículum escolar se configura con una serie de conocimientos seleccionados y dispuestos conforme a los principios de la modalidad paradigmática. Y como tales pretende transmitirlos, incluso cuando aborda la "alfabetización audiovisual" y ahora también la "alfabetización digital". A este propósito se establece un complejo dispositivo metodológico de enseñanza a fin de asegurar la transmisión fiel de aquellos contenidos, con los cuales no es fácil, al menos académicamente, producir relatos imaginativos.

Se podría, pues, afirmar que a mayor fidelidad y rigor en el medio de transmisión, menos necesarios son los dispositivos didácticos para que el usuario permanezca "conectado". ¿No es éste el principio en el que se fundan las expectativas formativas (y de negocio) en torno al e-learning? Otro debate muy distinto sería discernir cuánto se aprende y de qué naturaleza son los aprendizajes adquiridos interactuando en la red, aspectos bastante discutidos y analizados en el caso de los aprendizajes escolares. En definitiva, lo novedoso del e-learning no es la unueva pedagogía", sino una logística con la que gestionar la convergencia de servicios como el diseño gráfico, elaboración y comercialización de contenidos, auditorías que certifiquen la calidad del producto, las tutorías, evaluaciones garantes de la acreditación, etc. Y la confluencia de todos estos elementos constituye lo que se viene denominando entornos virtuales de aprendizaje, los cuales representan ya una importante línea de negocio y todo un reto para las instituciones de enseñanza presencial. Ahora bien, aquella logística marca los itinerarios a seguir en dicho entorno de modo que ¿recorrerlos es garantía suficiente de aprendizaje?

\subsection{Los aprendizajes del aprendiz de cibernauta}

La paradoja referida en este epígrafe es que, a través de las tecnologías se ha instaurado una tecnopedagogía, considerada autosuficiente para formar a los ciudadanos en el paradigma informacional emergente. El aporte de la institución escolar a este nuevo universo, como mucho, no debe pasar de lo meramente instrumental, las habilidades mínimas para acceder a las máquinas de la información. Lo sustantivo, lo verdaderamente importante se ofrece mediante la tecnopedagogía, cuyo discurso es autosuficiente tanto en lo estratégico como en los contenidos, y al usuario sólo se le exigen unos mínimos: económicos, de tiempo disponible para contemplar el fluir del relato electrónico y unas destrezas para activarlo. En palabras de Reig $(2001,76)$, se «debe procurar que sea el discurso de los 
propagandistas e ideólogos del éxtasis cibernético el que predomine con mucha distancia sobre los demás...". Mas si este horizonte educativo de los cibernautas no resulta demasiado halagüeño, habrá que fundamentar alternativas más sólidas.

La cuestión de fondo no es tanto el equipamiento tecnológico de la escuela ni cuánto se utiliza, sino más bien qué tipo de ciudadano se pretende educar para la sociedad de nuestros días mediante prácticas más creativas y solidarias. Y, desde luego, este modelo ya no se corresponde con el formado por la escuela mediante la enseñanza reglada, tal como hoy la conocemos. El prototipo que ahora se ensalza es aquel que, con el apoyo de las TIC, se construye a sí mismo en un solipsismo encantado por experimentar, cada poco tiempo, con nuevos inventos tecnológicos. Al sujeto se le ofrece una masa ingente de contenidos desregulados y caracterizados como "lo último", ante los que sólo debe exponer su capacidad de "autoaprendizaje». Por cierto, ¿alguien podría imaginarse una expresión más cómplice y sumisa al discurso tecnocientífico dominante? Para muestra un pequeño ejemplo de lo que piensan los encuestados del trabajo que realizamos sobre la "cultura tecnológica" (ver nota 10), ante una pregunta con tantas connotaciones como la siguiente: ¿Qué es la brecha tecnológica? Cuestión contestada únicamente por el $20 \%$, incluyendo a los que decían "Nunca he oído hablar de esto" o expresiones semejantes. Ninguna de las respuestas recogidas se aproxima a la noción de lo que se entiende por brecha tecnológica, como se desprende del siguiente extracto:

Supongo que será el espacio que existe entre la era actual o tecnológica y eras anteriores.

Un contratiempo o "atasco» en algún tipo de avance tecnológico o digital.

Quedarse atascado en la tecnología.

Respecto a los términos o adjetivos a los que asocian la "brecha tecnológica", tan sólo dos hablan de pobreza y otro de diferencia, los restantes mencionan digital, ruptura o distancia que no vienen demasiado al caso. Cierto que para utilizar las TIC, como sucede con la energía eléctrica, no es necesario conocer su naturaleza, pero teniendo en cuenta que vivimos en la sociedad del conocimiento y en un entorno pedagógico, cabe apuntar que no se está formando un pensamiento emancipado y correctamente organizado sobre el hábitat en el que viven, más bien parece todo lo contrario, alienado y desestructurado. Pues el aprendiz de cibernauta no parece ser sensible ni siquiera a una cuestión tan relevante como la referida brecha tecnológica.

Si éste es el sustrato, ¿de qué tipo de conocimiento se están apropiando los usuarios de las TIC? Y cuando éstas se disponen con propósitos pedagógicos como en el caso de los entornos virtuales de enseñanza, ihasta qué punto ese bagaje interfiere los aprendizajes? Comparto la opinión de los numerosos autores que piensan que para comprender pedagógicamente los entornos virtuales de aprendizaje, el modelo teórico "más apropiado es el denominado enfoque sociocultural" de Vigotsky y los desarrollos posteriores de su pensamiento originario. Dichos entornos 
se atienen a "la definición de un sistema de actividad colaborativa, la presencia de zonas de desarrollo próximo identificadas por los diferentes niveles de competencia de cada uno de los sujetos participantes, el concepto de interacción y la idea de contextualización" (García del Dujo y Martín García, 2002, 75).

Totalmente de acuerdo porque ésta es una línea de pensamiento consolidada, el problema surge cuando de la aplicación del modelo en una experiencia de entorno virtual de enseñanza, se concluye sin demasiado detalle que el éxito obtenido supera con creces el inicialmente previsto. La valoración precedente está referida a una experiencia universitaria en la que se evaluaron los siguientes aspectos: "asistencia a las sesiones teóricas y prácticas, elaboración de la página web personal, participación en el vídeo, trabajos colgados en la página web del proyecto y, si alguna parte fallaba, el recurso del examen..." (Álvarez, 2000, 97). Por muy buenos que sean los productos elaborados y colocados en la web, ¿de qué tipo y con cuánta solidez se ha transferido conocimiento entre el sistema técnico, el profesorado y el aprendiz? Mis dudas surgen, en primer lugar, a partir de la afirmación de Bruner $(2004,127)$, según la cual en el modelo vigotskiano «una de las principales herramientas es el lenguaje y las reglas de su uso". Y, por otro lado, estas herramientas ponen en tensión dialéctica a los sistemas que interaccionan y no sólo a la estructura cognitiva del aprendiz (Fichtner, 2002, 14 y ss.). Por tanto, ¿cómo responde a estas tensiones el entorno virtual que está programado? ¿Es suficientemente valioso con que el aprendiz sepa hacer una página web o se maneje en un foro de discusión? ¿No estamos ante un conocimiento demasiado instrumental y no el más abstracto y formal que se supone favorecen las TIC?

\section{A MODO DE CONCLUSIÓN}

Nuestro hábitat inmediato ya no es el "bosque virgen" evocado y añorado por don Miguel de Unamuno. Es un hábitat plagado de artefactos capaces incluso de "dialogar" entre ellos, facilitándonos a los humanos la vida como nunca antes se había conocido. Sin embargo, también hemos de reconocer que dicho hábitat nos impone un estilo de vida que encierra numerosas incógnitas y, en lo relativo a la educación, nos enfrenta al espejismo del aprendiz electrónico. Incertidumbres que, por supuesto, no son nuevas, puesto que cada época histórica ha debido replantearse qué pretendía para la educación de sus ciudadanos. No obstante, ahora resulta incómodo y hasta "políticamente incorrecto" hablar de tales dilemas, sacar a relucir las incongruencias y contradicciones de una sociedad complacida en reconocerse acríticamente con su estadio de desarrollo tecnológico. Pero esta actitud no facilita, sino que más bien complica, el abordar un asunto tan crucial en la relación de las TIC con la educación como es: ¿Cómo y de qué manera la institución escolar puede disponer las TIC en las prácticas de enseñanza, de modo que articule una oferta de educación acorde a los requerimientos de la sociedad actual? 
Se trata de cuestiones que siguen pendientes desde que se pretendió lo propio con el cine, la fotografía, el cómic, la prensa, la televisión, la informática y ahora Internet. El problema es tan complejo que las respuestas no han pasado de ser, la mayoría de las veces, experiencias locales basadas en el voluntarismo de los actores más inquietos o proyectos puntuales de investigación y, en lo teórico, ensayos parciales legitimadores del discurso hegemónico. Pero esto ya no es suficiente ni tampoco coherente con las circunstancias en las que se desenvuelve el ciudadano de las sociedades de nuestros días. El desafío aún pendiente es construir un modelo formal que, sin renunciar a lo primigenio de la educación, sirva de guía para unas prácticas en las que los artefactos del momento aporten a los distintos actores escolares su especificidad. Un modelo que contemple las condiciones de vida de los ciudadanos en un hábitat trabado por tecnologías de todo tipo que le proporcionan unas experiencias nuevas (Buckingham, 2000), junto a otras que no lo son tanto porque sencillamente no están sujetas al "orden tecnológico". En definitiva, un modelo muy atento a la naturaleza y consecuencias de la relación que el sujeto mantiene con su entorno, puesto que lo que cambia es esa relación modificando, a su vez, los elementos que intervienen en ella.

Parece razonable que el modelo fomente el aprender a convivir en un hábitat cargado de estímulos proporcionados por poderosas máquinas, y aprender a seleccionar pues algunos de aquéllos entrañan riesgos para el equilibrio ecológico y, por tanto, riesgo para la propia supervivencia según se recoge ya en diversos trabajos (Luján y Echeverría, eds., 2004). En este sentido la educación debería alejarse tanto de las posiciones esencialistas como de las orientaciones pedagógicas instrumentalistas, para centrarse en lo que hemos llamado "brecha endógena" (distancia que separa al sujeto del artefacto tecnológico que maneja, incluso cuando lo hace como usuario "experto"). Advirtiendo que la centralidad de este objeto sólo adquiere verdadero sentido si se sitúa cultural, histórica, política y científicamente en el hábitat en el que se desenvuelve el ciudadano. Parafraseando a García Carrasco y García del Dujo $(2001,411)$, diríamos que dicho modelo teórico debe facilitar que las prácticas escolares desentrañen ese conjunto de relaciones, para que deje de ser una "caja negra" que "el sujeto emplea pero no comprende" convirtiéndola en un objeto cultural con significación plena.

Desde el punto de vista pedagógico, ello implica trabajar en las aulas tanto con las herramientas que ofrece hoy el universo de las TIC como, de modo muy especial, con los discursos y las prácticas que ellas diseminan. A partir de las habilidades y conocimientos espontáneos adquiridos por los estudiantes, ir reconstruyendo el sentido de sus relaciones y prácticas no tanto en función del "paraíso virtual" prometido por el sistema técnico como de las condiciones virtuales y también físicas que rigen sus vidas. El currículum, con todos sus componentes curriculares, debe contribuir a dar sentido a cuestiones de la siguiente naturaleza: lógica a la que responde el desarrollo tecnológico, relaciones posibles entre las distintas estructuras discursivas adoptadas por las TIC y los estilos de pensamiento que fomentan, dónde posicionarse y cómo orientarse, en tanto que sujeto, en el "no 
lugar" que le presentan las telecomunicaciones (por ejemplo, en una plataforma de formación), implicaciones semánticas y estéticas de las composiciones icónicas que ofrecen los diferentes soportes electrónicos, riesgos y virtudes de distinto orden inherentes a las relaciones -individuales y colectivas- trabadas por las telecomunicaciones, etc. Para reforzar esta línea es preciso reorientar también la investigación de campo sobre el equipamiento de los centros escolares o el diseño de nuevos productos educativos, hacia estudios etnográficos sobre cómo y qué aprenden; en suma, cómo interpretan y estructuran la abundante información desde sus contextos de vida (Tobin, 2000, 140) que acontece en un mundo cuya materialidad se representa en códigos binarios.

En definitiva, gran parte de este trabajo, a nuestro entender, debe abordarse desde el espacio escolar en la medida que sigue siendo, pese a sus muchos puntos críticos, la única institución con capacidad para acometer con solvencia la formación de los ciudadanos que deben habitar y cuidar el mundo actual. La institución escolar, en suma, maneja el conocimiento científico del que emergen las TIC y además dispone de las herramientas formales para deconstruir los discursos encantados que sobre las TIC fluyen por todas partes. Para lo cual es imprescindible devolverle a esa institución parte de la confianza, la calma de la reflexión cognoscitiva y de la credibilidad que tan acríticamente hemos derivado hacia lo que hoy representa el sistema técnico. Para que esto sea posible es urgente repensar el entramado institucional de la escuela (conjunto de normas y reglas explícitas e implícitas), a fin de dotarla de una organización más receptiva a la naturaleza funcional de las tecnologías. Dicho de otro modo: ¿Cómo seguir hablando propiamente de escuela cuando en ésta los ordenadores no se localicen en el uaula de informática»? En definitiva, si las TIC liberan de las tareas memorísticas y rutinarias, ¿qué nuevos aprendizajes y actividades deben ocupar ese vacío?

\section{Bibliografía}

Álvarez, A. (2000) Hacia un enfoque sociocultural de la Educación Abierta: una lección multimedia sobre identidad cultural en el proyecto europeo inter-universitario Pegasus, Cultura y Educación, 20, 81-102.

BAllestero, F. (2002) La brecha digital. El riesgo de exclusión en la Sociedad de la Información. Madrid, Fundación Retevisión-Auna.

BATESON, G. (1999) Una unidad sagrada. Barcelona, Gedisa.

Broncano, F. (2000) Mundos artificiales. Filosofía del cambio tecnológico. Barcelona, Piados.

BRUNER, J. (2004) Realidad mental y mundos posibles. Barcelona, Gedisa.

Buckingham, D. (2000) Más allá de la dependencia: Hacia una teoría de la Educación para los Medios, Comunicar, 14, 57-62.

Bunge, M. (2002) Crisis y reconstrucción de la filosofía. Barcelona, Gedisa.

CABrillo, F. (2000) Nueva y vieja economía, Nueva revista de política, cultura y arte, 70, 8184.

Castells, M. (2001) La galaxia Internet. Madrid, Areté. 
Castelis, M. e Himanen, P. (2002) El Estado del bienestar y la sociedad de la información. Madrid, Alianza Editorial.

DELORS, J. (2001) La educación encierra un tesoro. Madrid, Santillana-UNESCO.

ECHEVERRía, J. (2003) La revolución tecnocientífica. Madrid, Fondo de Cultura Económica.

FICHTNER, B. (2002) Enseñar y aprender. Barcelona, Octaedro.

García Carrasco, J. y García Del Dujo, A. (2001) Teoría de la educación, vol. II. Salamanca, Ediciones Universidad de Salamanca.

García del Dujo, A. y Martín García, A. (2002) Caracterización pedagógica de los entornos virtuales de aprendizaje, Teoría de la Educación, 14, 67-92.

GIL, Ph. (2001) E-Formación. Bilbao, Ediciones Deusto.

GiMENO, J. (2001) Educar y convivir en la cultura global. Madrid, Morata.

- (2003) El alumno como invención. Madrid, Morata.

HARGREAVES, A. (2003) Enseñar para la sociedad del conocimiento: educar para la creatividad, en HARGREAVES, A. (ed.). Enseñar en la sociedad del conocimiento. Barcelona, Octaedro.

Lankshear, C. y Knobel, M. (2003) New Literacies. Philadelphia, Open University Press.

LLANO, A. (2000) Nueva Revista de política, cultura y arte, 70, 16-24.

Llompart, J. (2002) Prólogo al libro de CERF, SizA y CHOMSKY. Sociedad del futuro. Barcelona, Círculo de Lectores.

López Cerezo, J. A. y SÁnchez Ron, J. M. (eds.) (2001) Ciencia, Tecnología, Sociedad y Cultura en el cambio de siglo. Madrid, Biblioteca Nueva.

Luján, J. L. y ECheverRíA, J. (eds.) (2004) Gobernar los riesgos. Ciencia y valores en la sociedad del riesgo. Madrid, OEI-Biblioteca Nueva.

MarTín, C. (1999) La posición tecnológica de la economía española en Europa, Papeles de Economía Española, 81, 2-20.

Mattelart, A. (2000) Historia de la utopía planetaria. Barcelona, Piados.

Quintanilla, M. A. (1989) Tecnología: Un enfoque filosófico. Madrid, Fundesco.

RAMONET, I. (2000) La tecnología: revolución o reforma. El caso de la información. Navarra, Hiru.

REIG, A. (2001) El éxtasis cibernético. Madrid, Ediciones Libertarias.

RifKIN, J. (2000) La era del acceso. La revolución de la nueva economía. Barcelona, Piados.

San Martín, A. (1995) La escuela de las tecnologías. Valencia, Servicio de Publicaciones de la Universidad de Valencia.

SAnz-Magallón, J. M. (2000) ¿Qué es la Sociedad del Conocimiento? Nueva Revista de política, cultura y arte, 70, 9-15.

SARRAmona, J. (2000) Los retos de las nuevas tecnologías para la educación a distancia, Teoria de la Educación, 12, 13-27.

SENNETT, R. (2000) La corrosión del carácter. Barcelona, Anagrama.

TerCeIro, J. B. y MATÍAs, G. (2001) Digitalismo. El nuevo borizonte sociocultural Madrid, Taurus. ToBIN, J. (2000) Good guys don't wear hats. London, Teachers College Press.

VAIZEY, J. (1967) La educación en el mundo moderno. Madrid, Ediciones Guadarrama.

VÁzQuez, G. (2003) Sociedad-Red, ciudadanía cognitiva y educación, Revista de Educación, Núm. Extraordinario, 13-31. 